\title{
Double-edged alliance: mitochondrial surveillance by the UPS and autophagy
}

Article

Accepted Version

Creative Commons: Attribution-Noncommercial-No Derivative Works 4.0

Franz, A., Kevei, É. and Hoppe, T. (2015) Double-edged alliance: mitochondrial surveillance by the UPS and autophagy. Current Opinion in Cell Biology, 37. pp. 18-27. ISSN 0955-0674 doi: https://doi.org/10.1016/j.ceb.2015.08.004 Available at https://centaur.reading.ac.uk/65873/

It is advisable to refer to the publisher's version if you intend to cite from the work. See Guidance on citing.

To link to this article DOI: http://dx.doi.org/10.1016/j.ceb.2015.08.004

Publisher: Elsevier

All outputs in CentAUR are protected by Intellectual Property Rights law, including copyright law. Copyright and IPR is retained by the creators or other copyright holders. Terms and conditions for use of this material are defined in the End User Agreement.

\section{www.reading.ac.uk/centaur}

\section{CentAUR}

Central Archive at the University of Reading

Reading's research outputs online 


\title{
Double-edged alliance: Mitochondrial surveillance by the UPS and autophagy
}

\author{
André Franz ${ }^{1, *}$, Éva Kevei ${ }^{1, *}$, and Thorsten Hoppe ${ }^{1}$
}

${ }^{1}$ Institute for Genetics and Cologne Excellence Cluster on Cellular Stress Responses in Aging-Associated Diseases (CECAD), University of Cologne, Joseph-Stelzmann Str. 26 50931 Cologne, Germany

*Theses authors contributed equally to the preparation of the manuscript

Correspondence should be addressed to T.H.

thorsten.hoppe@uni-koeln.de Phone:

+49221478 84218

Fax: $\quad+4922147884217$ 
Abstract

Mitochondria provide an essential role in the maintenance of cellular homeostasis with regard to energy generation, redox signaling, and programmed cell death. Consequently, fast adaptation to metabolic changes associated with developmental demands or stress induction requires a balanced coordination of mitochondrial biogenesis and removal of damaged mitochondria. Impaired mitochondrial maintenance is causally linked to many human pathologies and ageing, including diabetes, cancer, and neurodegenerative diseases. Thus, it is of fundamental importance to understand cellular surveillance mechanisms that support a healthy mitochondrial network. In this review, we discuss the role of ubiquitin-dependent protein degradation in mitochondrial functionality.

Introduction 
Mitochondria form an essential compartment important to maintain cellular homeostasis in eukaryotic organisms. Besides supplying the cell with ATP, mitochondria play a central role in anabolic and catabolic processes as well as in cellular signaling pathways. Damaging agents from extrinsic or intrinsic sources contribute to mitochondrial impairment and thus endanger cellular health and viability. Mitochondria possess intrinsic mechanisms to either refold or terminally degrade non-functional or damaged proteins. Genetic or pharmacological induction of mitochondrial stress initiates the expression of mitochondria- and nuclear-encoded genes to compensate the toxic effects. Recently, an inter-organellar signaling cascade has been described between mitochondria and the nucleus involving the conserved transcription factor ATFS1 [1]. This transcriptional communication indicates intricately balanced cellular response mechanisms, which evolved to assure mitochondrial integrity. In addition to mitochondriaspecific quality control pathways [2], cytosolic protein degradation emerges as a critical factor supporting mitochondrial homeostasis (Box 1). Intriguingly, recent studies identified ubiquitinmediated protein degradation pathways that keep control over multiple aspects of mitochondrial functionality. Failure of mitochondrial surveillance supported by the ubiquitin/proteasomesystem (UPS) and autophagy (termed mitophagy) are causally linked to severe neurodegenerative diseases such as Parkinson's, Alzheimer's, and Huntington's disease (PD, AD, HD) [3]. Notably, other age-related pathologies, including diabetes mellitus and cancer, are also accompanied with functional decline of mitochondrial metabolism. In this review we focus on mitochondrial surveillance mechanisms provided by cytosolic protein degradation pathways governed by ubiquitin (Figure 1).

\section{Proteasomal degradation ensures a dynamic mitochondrial network}

Mitochondria assemble a highly dynamic and interconnected network that is constantly modified by fission and fusion events. The dynamic nature of the mitochondrial network provides an elegant mechanism controlling its functionality [4]. Damaged fractions can be segregated by fission events that promote the budding of mitochondrial membranes, enabling subsequent degradation of the compromised compartments. Alternatively, fusion with the healthy mitochondrial pool can complement a mitochondrion's functional deficiency. Respective regulatory factors determining mitochondrial morphology by dynamic fission and fusion have been identified. Dynamin-related proteins (Drp1 in mammals, Dmn1 in yeasts) promote mitochondrial fission and catalyze the segregation of a continuous mitochondrion into separated functional fragments. In contrast, mitofusins (Mfn1 and Mfn2 in mammals, Fzo1 in yeast) promote fusion of individual mitochondria. Both fission and fusion events underlie the cellular control by ubiquitin-mediated regulation of Drp1/Dnm1 or mitofusins [5] (Figure 1, Table 1). 
Several E3 ubiquitin ligases have been identified to define the dynamic mitochondrial network (Table 1, references therein). On one hand, degradation of fission promoting Drp1/Dnm1 and Fis1 proteins is supposed to promote fusion and elongation of mitochondria. Conversely, targeted degradation of mitofusins facilitates mitochondrial fragmentation (Table 1, references therein). In addition to ubiquitin-mediated turnover of mitofusins, non-proteolytic mechanisms have been identified, involving ubiquitin-dependent oligomerization and thus activation of mitochondrial fusion [6], [7]. Some E3 ligases selectively target several protein substrates, illustrating that the regulation of mitochondrial dynamics is finely tuned and multilayered [6,8]. In line with this idea, the metabolic or developmental status critically influence the mitochondrial morphology and dynamics $[9,10]$. Remarkably, it remains largely elusive how the activity of particular E3 ligases and DUBs is regulated at mitochondria. It will be important to uncover the molecular mechanisms that integrate ubiquitylation and deubiquitylation activity into the cellular signalling pathways that sense and modify mitochondrial dynamics [9]. Nonetheless, ubiquitinmediated protein degradation is vital in controlling the mitochondrial network, which is further modulated by deubiquitylating enzymes (DUBs) that regulate fission and fusion events [6], [11]- [13] (Box 1).

In addition to fission-fusion balance, the dynamics and integrity of the mitochondrial network strictly depends on active transport along the microtubule (MT) cytoskeleton, facilitating effective distribution and energy supply. Mitochondrial transport is particularly important in neurons to coordinate efficient distribution between the cell body and the distal synapse. Miro is a component of the protein complex that links mitochondria to MT-associated motor proteins [14]. Intriguingly, Miro has been identified as a target of the UPS, regulating mitochondrial transport and axonal distribution [15], [16]. Consequently, loss of Miro or the respective E3 ligase Parkin disturb mitochondrial transport in neurons as well as mitochondrial distribution in other cell types, affecting the morphology and functionality of the mitochondrial network [15], [16].

\section{Protein quality control at mitochondria is executed by MAD}

Besides other regulatory functions, the UPS is fundamental in maintaining cellular protein homeostasis (proteostasis) by degradation of aberrant proteins both in the cytosol and the nucleus. Ubiquitin-dependent degradation also triggers proteostasis in other cellular compartments including endosymbiotic mitochondria and plastids [17]. Recently, a dedicated proteolytic machinery has been characterized that catalyzes the degradation of mitochondriaassociated proteins by the cytosolic proteasome (mitochondria-associated protein degradation, MAD) [18]-[21] (Figure 1). Accumulation of aberrant and damaged proteins inside and outside of mitochondria is linked to functional decline, threatening cellular health and viability. Accordingly, many human disorders are linked to impaired mitochondrial proteostasis (Table 2). 
Proteins localized in the inner- and outer mitochondrial membrane (IMM, OMM), as well as the inter-membrane space (IMS) are degraded by the cytosolic UPS [22]-[26] (Figure 1). The exact mechanism involving the recognition and presentation of proteins localized in the matrix space, IMM, or IMS remains to be discovered. Proteases and membrane translocons inside these subcompartments are activated by the mitochondrial unfolded protein response (UPR ${ }^{\text {mit}}$ ) since they play a vital role in proteostasis [27]-[29]. In analogy to UPS-dependent degradation of proteins accumulating in the endoplasmic reticulum (ER-associated protein degradation, ERAD), MAD is involved in translocation of substrates across/from the OMM to enable transfer to the cytosolic proteasome (Figure 1). Similarly to ERAD, the highly conserved ubiquitindirected segregase Cdc48/p97/VCP (hereafter named Cdc48/p97) facilitates substrate translocation from the OMM [30] [31]. Upon induction of mitochondrial protein stress, the cofactor Vms1 relocalizes from the cytosol to mitochondria, which is required for Cdc48/p97 recruitment to the mitochondrial membrane [25]. Consistent with the concept of stress-induced mitochondrial degradation, loss of Vms 1 sensitizes yeast and $C$. elegans towards stress conditions. In contrast, however, Vms 1 is dispensable for Cdc48/p97-dependent regulation of mitochondrial morphology in otherwise unstressed conditions [32]. Thus, Cdc48/p97 presumably affects multiple aspects of mitochondrial function, which might be modulated by Vms1. The observation that Cdc48/p97 and Vms1 are able to attenuate cytotoxic aspects of

Alzheimer's disease further illustrates the relevance of UPS-mediated mitochondrial proteostasis in neurodegeneration [33]. Upon pharmacological uncoupling of proton transport from ATPsynthesis, several mitochondrial proteins are ubiquitylated [34], [35]. Cdc48/p97dependent proteasomal degradation of ubiquitylated mitofusins facilitates mitochondrial fragmentation, which in turn promotes the clearance of affected mitochondria by mitophagy [30], [36] (Figure 1). Ccd48/p97 thus forms an essential bridge between safeguarding mitochondrial function through fission-fusion balance or the terminal removal of damaged mitochondria by autophagy [37].

\section{PINK1/Parkin orchestrates proteasomal degradation and mitophagy}

In contrast to turnover of damaged proteins, complete proteolysis of entire mitochondria is mediated via autophagy. Under physiological conditions mitochondrial autophagy (mitophagy) is involved in adjusting mitochondrial mass for the metabolic needs of the cell and also removes mitochondria during differentiation processes. In most animals, paternal mitochondria are actively eliminated through selective mitophagy after fertilization of the oocyte, which ensures maternal inheritance of mitochondrial DNA [38], [39]. On the other hand, mitophagy provides an essential quality control mechanism in mitochondrial proteostasis maintenance. When mitochondria become damaged, they lose their membrane potential and are segregated from the mitochondrial network before autophagosomal engulfment and lysosomal degradation (Figure 1). The E3 
ubiquitin ligase Parkin and the PTEN-induced putative kinase protein 1 (PINK1) cooperate in targeting damaged mitochondria for degradation [40]. The Ser/Thr kinase PINK1 phosphorylates both Parkin and ubiquitin, which leads to the activation and mitochondrial recruitment of the E3 ligase [41]-[43]. Moreover, phosphorylated ubiquitin chains on the mitochondria act as Parkin receptor and trigger further cycles of Parkin translocation to the damaged organelle [44]. PINK1mediated phosphorylation of mitofusin 2 provides an additional critical step in mitochondrial Parkin recruitment [45], suggesting a mutual crosstalk between both protein modification systems in mitophagy initiation. Upon stress-induced activation of mitophagy Parkin ubiquitylates several mitochondrial substrates [34]. Ubiquitylation of mitochondrial proteins of the IMM, OMM, and IMS serves as degradation signal for turnover by the 265 proteasome, however, it also recruits the autophagic machinery to specifically recognize and remove dysfunctional mitochondria (Figure 1). It is likely that Parkin-induced ubiquitylation and proteasomal degradation of several OMM proteins precedes the initiation of mitophagy and interfering with proteasomal removal of these mitochondrial proteins attenuates autophagosomal degradation of mitochondria [46] [37]. Indeed, Parkin-mediated proteasomal turnover of mitofusins is crucial in fission-driven separation of damaged mitochondria parts, leading to selective ubiquitylation of dysfunctional mitochondria [36], [45].

Deubiquitylating enzymes (DUBs) oppose the activity of E3 ligases by removing ubiquitin molecules attached to substrate proteins (Box 1). So far only few DUBs were functionally linked to mitophagy (Table 1). USP8 is involved in promoting Parkin recruitment to the mitochondria through direct deubiquitylation of the E3 ligase [47]. USP15 and USP30 inhibit mitophagy by deubiquitylating Parkin targets on the mitochondrial surface [13], [48], [49], (Table 1). Interestingly, chains of phosphorylated ubiquitin were suggested to be resistant to DUBmediated hydrolysis thus amplifying the degradation signal generated by PINK1/Parkin [50].

The Parkin-generated ubiquitin coat on mitochondria is a major driving force in the recruitment of the autophagic membrane around the dysfunctional organelles (Figure 1). Ubiquitin-binding autophagy receptors such as p62, optineurin or NBR1 [46], [51]-[53] are recruited to the damaged organelle where they simultaneously bind to the ubiquitylated cargo and to the autophagosomal membranes. A common element of all autophagy receptor proteins is the LIRmotif that directly bind LC3 family proteins on the surface of the growing engulfment membrane, initiating autophagic removal of the cargo [54]. After internalization of the mitochondria, autophagosomes fuse with the lysosomes and degrade the content of the vesicles by hydrolytic enzymes (Figure 1).

PINK1 and Parkin are involved in the recently discovered alternative quality control mechanism that uses the vesicular trafficking pathway to remove damaged mitochondrial components. Mitochondria-derived vesicles, that contain selectively incorporated mitochondrial proteins directly 
fuse with late endosomes or multivesicular bodies for subsequent degradation in lysosomes [55]. Although PINK1 and Parkin seem to take the lion's share of mitophagy regulation upon excessive mitochondria damage [34], recent results suggest the existence of alternative pathways, which likely drive physiological levels of mitophagy. Such an alternative mitochondrial clearance mechanism is observed during the differentiation of erythrocytes, where the maturation process results in autophagic elimination of organelles, including mitochondria [56], [57].

\section{Crosstalk between UPS and mitophagy}

Proteomics studies revealed that Parkin may regulate ubiquitylation of more than 100 mitochondrial proteins upon mitochondrial depolarization. Various components of the cytoplasmic mitochondrial surveillance machinery, including proteasome subunits, Cdc48/p97 and autophagy receptors, are also amongst Parkin targets [34]. This suggests the existence of an intricately balanced crosstalk between the UPS and autophagy, with PINK1/Parkindependent ubiquitylation providing the central node of mitochondrial proteostasis maintenance.

The most apparent link between the two proteolytic systems is the common use of ubiquitylation as degradation signal. Timely coordinated, UPS-dependent degradation of target proteins at mitochondria is essential for subsequent initiation of mitophagy. E3 ubiquitin ligases present at the mitochondrial surface, such as Parkin, Mulan, MARCH5/MITOL and RNF185 can ubiquitylate various targets on the organelle's surface. For instance, muscle-wasting stimuli in skeletal muscles induce mitophagy through Mulan-driven ubiquitylation and proteasomal degradation of the mitochondrial fusion protein Mfn2 [58], thus preceding autophagic clearance of mitochondria (Figure 1). PINK1-dependent regulation of protein turnover provides another example for the crosstalk between the UPS and selective autophagy. When PINK1 is targeted to healthy mitochondria it is rapidly degraded by the $\mathrm{N}$-end-rule degradation pathway in the cytoplasm, thereby limiting Parkin recruitment to the functional organelle [59].

UPS activity and the MAD pathway are crucial in maintaining mitochondrial homeostasis. Proteasome inhibition induces mitochondrial dysfunction accompanied by excessive mitochondrial fragmentation [60]-[62]. On the other hand, mitochondrial dysfunction can adversely affect the cytoplasmic protein degradation pathways [63], [64]. Signals generated by damaged mitochondria can dramatically alter the activity of UPS. Thus, impairment of mitophagy and subsequent increase in mitochondrial ROS production or decrease in ATPsupply has severe impact on overall fitness of the cell. Our recent work indicates that oxidative stress caused by impaired mitochondrial metabolism attenuates protein degradation at the $26 \mathrm{~S}$ proteasome (Figure 1). Accordingly, proteolytic defects of the UPS can be observed in human disorders linked to pathological mitochondrial metabolism [63]. While turnover of $\mathrm{N}$-end-rule and UFD-model 
substrates is reduced upon mitochondrial stress, degradation of mitochondrial proteins via the MAD pathway seems to be unaffected in primary patient cells (Figure 1) [63]. This data support the idea that different proteolytic branches of the cytoplasmic UPS might hold different sensitivity towards mitochondrial oxidative stress. Alternatively, the UPS might reinforce activity and/or localization of the $26 \mathrm{~S}$ proteasome especially under metabolic stress conditions, to ensure optimal quality control of the organelle when the proteolytic capacity of the cytoplasm is limited. In support of this idea, imbalances in mitochondrial protein import from the cytosol activates a cellular response supporting proteostasis through decreased de-novo protein synthesis and elevated proteasomal activity, due to enhanced proteasome assembly [65]. Increased ROS production caused by mitochondrial inhibition can also block the $26 \mathrm{~S}$ proteasome through oxidation-induced disassembly into $20 \mathrm{~S}$ core and $19 \mathrm{~S}$ regulatory particles. The reversible nature of the proteasomal assembly state suggests an adaptive response mechanism triggered by cellular stress [64], [65]. It is therefore intriguing to speculate that decreased UPS activity potentiates development and progression of metabolic diseases through a conserved mitochondrial surveillance response.

\section{Role of mitochondrial homeostasis in organismal development and health}

Mitochondria are key organelles for viability of eukaryotic cells. Consequently, functional decline of mitochondria has direct implications in human pathophysiology. Above altered cellular bioenergetics, mitochondria dysfunction also produces damaging agents and initiate cellular pathways, such as stress responses, proteolysis or cell death, which ultimately modify cellular homeostasis and cellular fate. Muscles and neuronal cells represent the most energydemanding tissues in the human body. Although mitochondria are present and essential for almost all cell types, the majority of human diseases associated with altered mitochondrial function, primarily affect the neuronal system, cardiac and skeletal muscle tissues (Table 2). Mitochondrial defects associated with elevated levels of oxidative stress have been linked to ageing and neurodegenerative diseases, such as AD, HD, and PD [66], [67]. Interestingly, the ubiquitin variant $\mathrm{UBB}^{+1}$ accumulates in brain tissues of $\mathrm{AD}$ patients, causing neuronal death [68]. Ectopic $\mathrm{UBB}^{+1}$ expression in yeast causes oxidative stress, fragmentation of the mitochondrial network as well as apoptosis. Importantly, increased expression of Cdc48/p97 or Vms1 alleviates the cytotoxic effects of $\mathrm{UBB}^{+1}$ [33]. Cdc48/p97 enhances the degradation of the toxic ubiquitin variant, while Vms1 expression reduces toxic effects on the mitochondria by a process involved in regulation of basic amino acid synthesis. UBB ${ }^{+1}$ co-exists with Vms1 in hippocampal neurons of AD patients, suggesting that MAD pathway components are crucial in fighting disease progression [33]. Similarly, overexpression of the proteasomal subunit RPN6, a stabilizing factor of the full 26S proteasome [69], has also been shown to surpass mitochondrial inhibition of cellular proteolysis at the proteasome [63]. These observations suggest that mitochondrial damage-induced cellular 
dysfunction can be efficiently counteracted by enhanced activation of the ubiquitin-mediated protein turnover, offering alternative target specificity in the treatment of mitochondria-linked diseases.

Besides the role of impaired mitochondrial functionality in human pathologies, mitochondrial integrity has far reaching implications on organismal development, health, and ageing.

Accordingly, the cellular content as well as dynamic morphology of mitochondria are carefully balanced by regulated biogenesis and mitophagy during both organismal ageing and in response to stress conditions [70]. Mild mitochondrial dysfunction triggers adaptive mechanisms including the UPR ${ }^{m i t}$, enhancing cellular health, and organismal fitness [71]. Interestingly, mitochondrial dysfunction in a defined tissue is capable of initiating this systemic response in distal tissues in $C$. elegans and Drosophila [72], [73]. In this regard, it is intriguing that sensing of energy status specifically in neurons coordinates mitochondrial morphology in distinct tissues [74]. Thus, the central nervous system likely acts as the topmost regulator of mitochondrial function in multicellular organisms, which is capable of overwriting systemic responses from other tissues [74]. The role of ubiquitin-mediated protein degradation in surveillance of mitochondrial function is evident, however, the connection to regulating systemic health and ageing remains elusive.

\section{Concluding remarks}

In contrast to cellular mechanisms ensuring mitochondrial functionality, our knowledge on the coexistence and crosstalk between distinct surveillance pathways is largely fragmentary. PINK1/Parkin promote mitochondrial fission through selective proteasomal degradation of mitofusins [36]. Conversely, more than 100 substrates are potentially ubiquitylated upon depolarization to trigger mitophagy [34], [46]. The signals that decide between degradation of mitochondrial proteins or the entire organelle are not known yet. It is intriguing to speculate that the amount and/or topology of ubiquitin chains attached to mitochondria might coordinate proteasomal targeting and autophagy via selective recruitment of specific ubiquitin receptors. Alternatively, MAD and mitophagy are probably activated through separated signaling cascades. Accordingly, phosphorylated ubiquitin has recently been suggested to serve as the decisive signal that initiates mitophagy through direct recruitment of selective autophagy receptors [75]. The cooperation with intrinsic mitochondrial proteostasis pathways as well as the integration of MAD and mitophagy into the UPR ${ }^{\text {mit }}$ demands further investigation [27], [28], [76]- [78]. Moreover, it is also important to uncover the signaling pathway that either activate or attenuate cytosolic proteasome activity upon mitochondrial dysfunction. Mechanistic insights into mitochondrial surveillance and the crosstalk between underlying signaling pathways will help to understand disease pathology and provide therapeutic strategies. 
Figure Legends, Table Legends, Content of boxes

\section{Figure1}

\section{Control of mitochondrial dynamics and removal of dysfunctional mitochondria by cytosolic protein degradation}

(a) Mitochondrial fission and fusion events shape the morphology of the mitochondrial network in eukaryotic cells. Ubiquitylation and deubiquitylation of critical regulator proteins is decisive of initiating mitochondrial fission (red) or fusion (blue), respectively. Several substrates have been shown to be degraded by the $26 \mathrm{~S}$ proteasome upon ubiquitylation. However, alternative pathways are also described involving ubiquitin-dependent oligomerization and protein-protein interaction. Regulation of mitochondrial morphology is vital for cellular health and survival and can also be modulated upon physiological adaption, such as cell division or differentiation. See text and Table1 for further details.

(b) Mitochondrial functionality can be threatened from intrinsic or extrinsic sources. Damaged proteins from inside and outside surfaces of mitochondria are degraded in a pathway relying on the cytosolic UPS, called the mitochondria-associated protein degradation (MAD). The precise recognition and translocation pathways of proteins from the Matrix, IMM, and IMS remain to be elucidated. Substrate proteins associated with the OMM require membrane dislocation by the ubiquitin-dependent segregase Cdc48/p97, enabling subsequent degradation by the proteasome. In turn, generation of reactive oxygen species (ROS) upon mitochondrial dysfunction can result of reduced proteasomal activity in the cytosol (UFD, and N-end rule substrates). Severely damaged mitochondria are removed by autophagic degradation (mitophagy). Herein, ubiquitylation of proteins in the OMM is recognized by dedicated adaptor proteins (autophagy receptors) that recruit the phagophore through interaction with ubiquitin and LC3, respectively. Completing maturation, an autophagosomal double-membrane engulfs mitochondria. Subsequent, fusion with the lysosome triggers the degradation of biomolecules.

See text and Table 1 for further information.

\section{Table 1}

UPS components regulating mitochondrial dynamics, mitochondria-associated degradation (MAD), and mitophagy 
The table summarizes components of the UPS that are implicated in the regulation of mitochondrial dynamics, the MAD pathway, or mitophagy. Experimental systems and specific substrate proteins are displayed wherever applicable.

\section{Table 2}

\section{Human pathologies linked to defects in mitochondrial protein quality control}

The table summarizes human pathologies that are linked to defects in mitochondrial morphology or protein quality control.

\section{Box1}

\section{Ubiquitin-mediated proteolysis by the UPS and autophagy}

Targeted protein degradation is fundamental for cellular function and viability. Selected protein turnover is a fast and powerful regulatory mechanism to inactivate signaling proteins or cellular determinants, e.g. to drive cell cycle progression or development. In addition, protein degradation is vital for the removal of non-functional or aberrant proteins to prevent cytotoxicity. Both major protein degradation pathways in eukaryotic cells, the ubiquitin-proteasome system (UPS) and autophagy, involve posttranslational modification of target proteins with ubiquitin. Ubiquitylation of substrates is catalyzed by an enzymatic cascade of ubiquitin-activating $(E 1)$, ubiquitin-conjugating (E2), and ubiquitin-ligating (E3) enzymes. Following ubiquitin conjugation to a substrate protein, ubiquitin-chains are formed by iterative linkage of one ubiquitin molecule to the other. Deubiquitylation by ubiquitin-hydrolases or DUBs serves as an important regulatory mechanism of chain length or topology. Ubiquitin-receptors bind to ubiquitin-chains assembled on target proteins and initiate their transfer and terminal degradation by the 26S proteasome. Alternatively, in a process that has been termed selective autophagy, ubiquitin-receptors can bridge to autophagic protein degradation by recognition of membrane-conjugated LC3 family protein (a ubiquitin-like molecule). LC3 is conjugated to the forming phagophore, a doublelayered membrane that eventually engulfs the ubiquitylated material, which can be aggregated proteins, entire organelles, or pathogenic bacteria. After maturation into an autophagic vesicle, fusion with the lysosome enables the degradation of biomolecules, including proteins, by lysosomal hydrolases. Interestingly, recent observations strongly suggest that both pathways, the UPS and autophagy, are tightly interconnected. First, loss of one degradation pathway can partially be compensated by the other, implicating functional redundancy. Moreover, the signaling promoting autophagosomal degradation underlies control by the UPS. In turn, proteasomes can be degraded 
via autophagy. Thus, it appears very likely that intricate crosscommunication between both ubiquitin-mediated protein degradation pathways exist, waiting to be deciphered.

\section{Acknowledgements}

We thank the members of our laboratory for critical discussion and helpful advice on the manuscript. T.H. is supported by the Deutsche Forschungsgemeinschaft (CECAD, FOR885, SFB635, KFO 286, and DIP8 grant 2014376) and the European Research Council (consolidator grant 616499). We apologize for not having cited valuable contributions due to size limitation.

\section{Competing interest}

The authors declare that they have no competing financial or personal interests.

\section{References}

[1] A. M. Nargund, C. J. Fiorese, M. W. Pellegrino, P. Deng, and C. M. Haynes, - Mitochondrial and Nuclear Accumulation of the Transcription Factor ATFS-1 Promotes OXPHOS Recovery during the UPRmt,II Mol. Cell, vol. 58, no. 1, pp. 123-133, 2015.

[2] M. J. Baker, T. Tatsuta, and T. Langer, -Quality Control of Mitochondrial Proteostasis,II Cold Spring Harb. Perspect. Biol., vol. 3, no. 7, pp. a007559-a007559, 2011.

[3] R. K. Lane, T. Hilsabeck, and S. L. Rea, -The role of mitochondrial dysfunction in agerelated diseases,II Biochim. Biophys. Acta - Bioenerg., 2015.

[4] M. Roy, P. H. Reddy, M. lijima, and H. Sesaki, -Mitochondrial division and fusion in metabolism,Il Curr. Opin. Cell Biol., vol. 33, pp. 111-118, 2015.

[5] M. Escobar-Henriques and T. Langer, -Dynamic survey of mitochondria by ubiquitin.,॥ EMBO Rep., vol. 15, no. 3, pp. 231-43, 2014.

[6] F. Anton, G. Dittmar, T. Langer, and M. Escobar-Henriques, -Two Deubiquitylases Act on Mitofusin and Regulate Mitochondrial Fusion along Independent Pathways,II Mol. Cell, vol. 49, no. 3, pp. 487-498, 2013.

[7] A. Sugiura, S. Nagashima, T. Tokuyama, T. Amo, Y. Matsuki, S. Ishido, Y. Kudo, H. M. McBride, T. Fukuda, N. Matsushita, R. Inatome, and S. Yanagi, - MITOL regulates endoplasmic reticulum-mitochondria contacts via Mitofusin2,॥ Mol. Cell, vol. 51, no. 1, pp. 20-34, 2013. 
[8] M. M. Cohen, E. a Amiott, A. R. Day, G. P. Leboucher, E. N. Pryce, M. H. Glickman, J. M. McCaffery, J. M. Shaw, and A. M. Weissman, -Sequential requirements for the GTPase domain of the mitofusin Fzo1 and the ubiquitin ligase SCFMdm30 in mitochondrial outer membrane fusion.,II J. Cell Sci., vol. 124, no. Pt 9, pp. 1403-1410, 2011.

[9] A. Carlucci, L. Lignitto, and A. Feliciello, - Control of mitochondria dynamics and oxidative metabolism by cAMP, AKAPs and the proteasome, II Trends Cell Biol., vol. 18, no. 12, pp. 604-613, 2008.

[10] P. Mishra and D. C. Chan, - Mitochondrial dynamics and inheritance during cell division, development and disease,\|l Nat. Publ. Gr., vol. 15, no. 10, pp. 634-646, 2014.

[11] A. Kinner and R. Kölling, - The yeast deubiquitinating enzyme Ubp16 is anchored to the outer mitochondrial membrane,\|l FEBS Lett., vol. 549, no. 1-3, pp. 135-140, 2003.

[12] R. Pan, N. Kaur, and J. Hu, - The Arabidopsis mitochondrial membrane-bound ubiquitin protease UBP27 contributes to mitochondrial morphogenesis, II Plant J., vol. 78, no. 6, pp. 1047-1059, 2014.

[13] C. N. Cunningham, J. M. Baughman, L. Phu, J. S. Tea, C. Yu, M. Coons, D. S. Kirkpatrick, B. Bingol, and J. E. Corn, -USP30 and parkin homeostatically regulate atypical ubiquitin chains on mitochondria,\|l Nat. Cell Biol., vol. 17, no. 2, pp. 160-169, 2015.

[14] X. Guo, G. T. Macleod, A. Wellington, F. Hu, S. Panchumarthi, M. Schoenfield, L. Marin, M. P. Charlton, H. L. Atwood, and K. E. Zinsmaier, -The GTPase dMiro is required for axonal transport of mitochondria to drosophila synapses, II Neuron, vol. 47, no. 3, pp. 379-393, 2005.

[15] X. Wang, D. Winter, G. Ashrafi, J. Schlehe, Y. L. Wong, D. Selkoe, S. Rice, J. Steen, M. J. Lavoie, and T. L. Schwarz, -PINK1 and Parkin target miro for phosphorylation and degradation to arrest mitochondrial motility,ll Cell, vol. 147, no. 4, pp. 893-906, 2011.

[16] S. Liu, T. Sawada, S. Lee, W. Yu, G. Silverio, P. Alapatt, I. Millan, A. Shen, W. Saxton, T. Kanao, R. Takahashi, N. Hattori, Y. Imai, and B. Lu, -Parkinson's disease-associated kinase PINK1 regulates miro protein level and axonal transport of mitochondria, II PLoS Genet., vol. 8, no. 3, pp. 15-17, 2012.

[17] Q. Ling and P. Jarvis, —Dynamic regulation of endosymbiotic organelles by ubiquitination,II Trends Cell Biol., vol. 23, no. 8, pp. 399-408, 2013.

[18] N. Livnat-Levanon and M. H. Glickman, _Ubiquitin-Proteasome System and mitochondria

- Reciprocity,II Biochim. Biophys. Acta - Gene Regul. Mech., vol. 1809, no. 2, pp. 80-87, 2011.

[19] E. B. Taylor and J. Rutter, -Mitochondrial quality control by the ubiquitin-proteasome system,\|l Biochem. Soc. Trans., vol. 39, no. 5, pp. 1509-1513, 2011.

[20] A. Neutzner, G. Benard, R. J. Youle, and M. Karbowski, -Role of the ubiquitin conjugation system in the maintenance of mitochondrial homeostasis, II Ann. N. Y. Acad. Sci., vol. 1147, pp. 242-253, 2008. 
[21] J.-M. Heo and J. Rutter, —Ubiquitin-dependent mitochondrial protein degradation., II Int. J. Biochem. Cell Biol., vol. 43, no. 10, pp. 1422-1426, 2011.

[22] V. Azzu and M. D. Brand, -Degradation of an intramitochondrial protein by the cytosolic proteasome.,Il J. Cell Sci., vol. 123, no. Pt 4, pp. 578-585, 2010.

[23] P. Bragoszewski, a. Gornicka, M. E. Sztolsztener, and a. Chacinska, -The UbiquitinProteasome System Regulates Mitochondrial Intermembrane Space Proteins,II Mol. Cell. Biol., vol. 33, no. 11, pp. 2136-2148, 2013.

[24] V. Azzu, S. A. Mookerjee, and M. D. Brand, -Rapid turnover of mitochondrial uncoupling protein 3.,\|l Biochem. J., vol. 426, no. 1, pp. 13-17, 2010.

[25] J.-M. Heo, N. Livnat-Levanon, E. B. Taylor, K. T. Jones, N. Dephoure, J. Ring, J. Xie, J. L. Brodsky, F. Madeo, S. P. Gygi, K. Ashrafi, M. H. Glickman, and J. Rutter, -A stressresponsive system for mitochondrial protein degradation., Il Mol. Cell, vol. 40, no. 3, pp. 465-480, 2010.

[26] E. S. Vincow, G. Merrihew, R. E. Thomas, N. J. Shulman, R. P. Beyer, M. J. MacCoss, and $\mathrm{L}$. J. Pallanck, - The PINK1-Parkin pathway promotes both mitophagy and selective respiratory chain turnover in vivo.,ll Proc. Natl. Acad. Sci. U. S. A., vol. 110, no. 16, pp. 6400-5, 2013.

[27] V. Jovaisaite and J. Auwerx, - The mitochondrial unfolded protein responsesynchronizing genomes,ll Curr. Opin. Cell Biol., vol. 33, pp. 74-81, 2015.

[28] M. W. Pellegrino, A. M. Nargund, and C. M. Haynes, -Signaling the mitochondrial unfolded protein response,\|l Biochim. Biophys. Acta - Mol. Cell Res., vol. 1833, no. 2, pp. 410-416, 2013.

[29] M. B. Jensen and H. Jasper, -Mitochondrial proteostasis in the control of aging and longevity,ll Cell Metab., vol. 20, no. 2, pp. 214-225, 2014.

[30] S. Xu, G. Peng, Y. Wang, S. Fang, and M. Karbowski, -The AAA-ATPase p97 is essential for outer mitochondrial membrane protein turnover., „l Mol. Biol. Cell, vol. 22, no. 3, pp. 291-300, 2011.

[31] A. Franz, L. Ackermann, and T. Hoppe, -Create and preserve: Proteostasis in development and aging is governed by Cdc48/p97/NCP, $\|$ Biochimica et Biophysica Acta Molecular Cell Research, vol. 1843, no. 1. pp. 205-215, 2014.

[32] M. Esaki and T. Ogura, -Cdc48p/p97-mediated regulation of mitochondrial morphology is Vms1p-independent,Il J. Struct. Biol., vol. 179, no. 2, pp. 112-120, 2012.

[33] R. J. Braun, C. Sommer, C. Leibiger, R. J. G. Gentier, V. I. Dumit, K. Paduch, T. Eisenberg, L. Habernig, G. Trausinger, C. Magnes, T. Pieber, F. Sinner, J. Dengjel, F. W. van Leeuwen, G. Kroemer, and F. Madeo, -Accumulation of Basic Amino Acids at Mitochondria Dictates the Cytotoxicity of Aberrant Ubiquitin, II Cell Rep., vol. 10, no. 9, pp. 1557-1571, 2015. 
[34] S. A. Sarraf, M. Raman, V. Guarani-Pereira, M. E. Sowa, E. L. Huttlin, S. P. Gygi, and J. W. Harper, -Landscape of the PARKIN-dependent ubiquitylome in response to mitochondrial depolarization.,॥ Nature, vol. 496, no. 7445, pp. 372-6, 2013.

[35] A. Ordureau, S. A. Sarraf, D. M. Duda, J.-M. Heo, M. P. Jedrychowski, V. O. Sviderskiy, J. L. Olszewski, J. T. Koerber, T. Xie, S. A. Beausoleil, J. A. Wells, S. P. Gygi, B. A. Schulman, and J. W. Harper, -Quantitative Proteomics Reveal a Feedforward Mechanism for Mitochondrial PARKIN Translocation and Ubiquitin Chain Synthesis, II Mol. Cell, vol. 56, no. 3, pp. 360-375, 2014.

[36] A. Tanaka, M. M. Cleland, S. Xu, D. P. Narendra, D. F. Suen, M. Karbowski, and R. J. Youle, -Proteasome and p97 mediate mitophagy and degradation of mitofusins induced by Parkin,II J. Cell Biol., vol. 191, no. 7, pp. 1367-1380, 2010.

[37] O. S. Shirihai, M. Song, and G. W. Dorn, -How Mitochondrial Dynamism Orchestrates Mitophagy,\|l Circ. Res., vol. 116, no. 11, pp. 1835-1849, 2015.

[38] M. Sato and K. Sato, —Degradation of paternal mitochondria by fertilization-triggered autophagy in C. elegans embryos, II vol. 37, no. November, pp. 1141-1144, 2011.

[39] a. Djeddi, S. Al Rawi, J. L. Deuve, C. Perrois, Y.-Y. Liu, M. Russeau, M. Sachse, and V. Galy, - Sperm-inherited organelle clearance in C. elegans relies on LC3-dependent autophagosome targeting to the pericentrosomal area,II Development, vol. 142, no. 9, pp. 1705-1716, 2015.

[40] A. Eiyama and K. Okamoto, -PINK1/Parkin-mediated mitophagy in mammalian cells, II Curr. Opin. Cell Biol., vol. 33, pp. 95-101, 2015.

[41] F. Koyano, K. Okatsu, H. Kosako, Y. Tamura, E. Go, M. Kimura, Y. Kimura, H. Tsuchiya, H. Yoshihara, T. Hirokawa, T. Endo, E. a Fon, J.-F. Trempe, Y. Saeki, K. Tanaka, and N. Matsuda, -Ubiquitin is phosphorylated by PINK1 to activate parkin.,Il Nature, vol. 510, no. 7503, pp. 162-6, 2014.

[42] L. A. Kane, M. Lazarou, A. I. Fogel, Y. Li, K. Yamano, S. A. Sarraf, S. Banerjee, and R. J. Youle, -PINK1 phosphorylates ubiquitin to activate parkin E3 ubiquitin ligase activity,\|l J. Cell Biol., vol. 205, no. 2, pp. 143-153, 2014.

[43] A. Kazlauskaite, C. Kondapalli, R. Gourlay, D. G. Campbell, M. S. Ritorto, K. Hofmann, D. R. Alessi, A. Knebel, M. Trost, and M. M. K. Muqit, -Parkin is activated by PINK1dependent phosphorylation of ubiquitin at Ser65.,II Biochem. J., vol. 460, no. 1, pp. 127-39, 2014.

[44] K. Okatsu, M. Kimura, T. Oka, K. Tanaka, and N. Matsuda, -Unconventional PINK1 localization to the outer membrane of depolarized mitochondria drives Parkin recruitment,\|l J. Cell Sci., vol. 128, no. 5, pp. 964-978, 2015.

[45] Y. Chen and G. W. Dorn, -PINK1-phosphorylated mitofusin 2 is a Parkin receptor for culling damaged mitochondria.,II Science, vol. 340, no. 6131, pp. 471-5, 2013.

[46] N. C. Chan, A. M. Salazar, A. H. Pham, M. J. Sweredoski, N. J. Kolawa, R. L. J. Graham, S. Hess, and D. C. Chan, -Broad activation of the ubiquitin-proteasome system by Parkin is critical for mitophagy, II Hum. Mol. Genet., vol. 20, no. 9, pp. 1726-1737, 2011. 
[47] T. M. Durcan, M. Y. Tang, J. R. Pérusse, E. A. Dashti, M. A. Aguileta, L. Mclelland, P. Gros, T. A. Shaler, D. Faubert, B. Coulombe, and E. A. Fon, -USP 8 regulates mitophagy by removing $\mathrm{K} 6$-linked ubiquitin conjugates from parkin,॥ vol. 33, no. 21, pp. 2473-2491, 2014.

[48] T. Cornelissen, D. Haddad, F. Wauters, C. Van Humbeeck, W. Mandemakers, B. Koentjoro, C. Sue, K. Gevaert, B. De Strooper, P. Verstreken, and W. Vandenberghe, -The deubiquitinase USP15 antagonizes Parkin-mediated mitochondrial ubiquitination and mitophagy., II Hum. Mol. Genet., vol. 23, no. 19, pp. 1-45, 2014.

[49] B. Bingol, J. S. Tea, L. Phu, M. Reichelt, C. E. Bakalarski, Q. Song, O. Foreman, D. S. Kirkpatrick, and M. Sheng, -The mitochondrial deubiquitinase USP30 opposes parkinmediated mitophagy., Il Nature, vol. 509, no. 7505, pp. 370-5, 2014.

[50] T. Wauer, K. N. Swatek, J. L. Wagstaff, C. Gladkova, J. N. Pruneda, M. A. Michel, M. Gersch, C. M. Johnson, S. M. V Freund, and D. Komander, -Ubiquitin Ser65 phosphorylation affects ubiquitin structure, chain assembly and hydrolysis, II vol. 34, no. 3, pp. 307-325, 2015.

[51] S. Geisler, S. Vollmer, S. Golombek, and P. J. Kahle, -UBE2N, UBE2L3 and UBE2D2/3 ubiquitin-conjugating enzymes are essential for parkin-dependent mitophagy., Il J. Cell Sci., vol. 65, pp. 3280-3293, 2014.

[52] D. P. Narendra, L. a. Kane, D. N. Hauser, I. M. Fearnley, and R. J. Youle, - p62/SQSTM1 is required for Parkin-induced mitochondrial clustering but not mitophagy; VDAC1 is dispensable for both,\|l Autophagy, vol. 6, no. 8, pp. 1090-1106, 2010.

[53] Y. C. Wong and E. L. F. Holzbaur, -Optineurin is an autophagy receptor for damaged mitochondria in parkin-mediated mitophagy that is disrupted by an ALS-linked mutation,\|l Proc. Natl. Acad. Sci., vol. 111, no. 42, pp. E4439-E4448, 2014.

[54] P. Wild, D. G. McEwan, and I. Dikic, -The LC3 interactome at a glance., „l J. Cell Sci., vol. 127, no. Pt 1, pp. 3-9, 2014.

[55] V. Soubannier, G. L. McLelland, R. Zunino, E. Braschi, P. Rippstein, E. a. Fon, and H. M. McBride, -A vesicular transport pathway shuttles cargo from mitochondria to lysosomes, Il Curr. Biol., vol. 22, no. 2, pp. 135-141, 2012.

[56] S. Honda, S. Arakawa, Y. Nishida, H. Yamaguchi, E. Ishii, and S. Shimizu, —Ulk1mediated Atg5-independent macroautophagy mediates elimination of mitochondria from embryonic reticulocytes., „l Nat. Commun., vol. 5, p. 4004, 2014.

[57] Y. Nishida, S. Arakawa, K. Fujitani, H. Yamaguchi, T. Mizuta, T. Kanaseki, M. Komatsu, K. Otsu, Y. Tsujimoto, and S. Shimizu, -Discovery of Atg5/Atg7-independent alternative macroautophagy.,Il Nature, vol. 461, no. 7264, pp. 654-658, 2009.

[58] S. Lokireddy, I. W. Wijesoma, S. Teng, S. Bonala, P. D. Gluckman, C. McFarlane, M. Sharma, and R. Kambadur, -The ubiquitin ligase Mul1 induces mitophagy in skeletal muscle in response to muscle-wasting stimuli,I Cell Metab., vol. 16, no. 5, pp. 613-624, 2012.

[59] K. Yamano and R. J. Youle, -PINK1 is degraded through the N-end rule pathway, Autophagy, vol. 9, no. 11, pp. 1758-1769, 2013. 
[60] K. Altmann and B. Westermann, - Role of essential genes in mitochondrial morphogenesis in Saccharomyces cerevisiae.,Il Mol. Biol. Cell, vol. 16, no. 11, pp. 54105417, 2005.

[61] L. Hofmann, R. Saunier, R. Cossard, M. Esposito, T. Rinaldi, and A. Delahodde, -A nonproteolytic proteasome activity controls organelle fission in yeast., „l J. Cell Sci., vol. 122, no. Pt 20, pp. 3673-3683, 2009.

[62] T. Rinaldi, R. Ricordy, M. Bolotin-Fukuhara, and L. Frontali, - Mitochondrial effects of the pleiotropic proteasomal mutation mpr1/rpn11: Uncoupling from cell cycle defects in extragenic revertants, Il Gene, vol. 286, no. 1, pp. 43-51, 2002.

[63] A. Segref, É. Kevei, W. Pokrzywa, K. Schmeisser, J. Mansfeld, N. Livnat-Levanon, R. Ensenauer, M. H. Glickman, M. Ristow, and T. Hoppe, -Pathogenesis of human mitochondrial diseases is modulated by reduced activity of the ubiquitin/proteasome system,ll Cell Metab., vol. 19, no. 4, pp. 642-652, 2014.

[64] N. Livnat-Levanon, É. Kevei, O. Kleifeld, D. Krutauz, A. Segref, T. Rinaldi, Z. Erpapazoglou, M. Cohen, N. Reis, T. Hoppe, and M. Glickman, -Reversible 26S proteasome disassembly upon mitochondrial stress, II Cell Rep., vol. 7, no. 5, pp. 13711380, 2014.

[65] L. Wrobel, U. Topf, P. Bragoszewski, S. Wiese, M. E. Sztolsztener, S. Oeljeklaus, A. Varabyova, M. Lirski, P. Chroscicki, S. Mroczek, E. Januszewicz, A. Dziembowski, M. Koblowska, B. Warscheid, and A. Chacinska, -Mistargeted mitochondrial proteins activate a proteostatic response in the cytosol,\|l Nature, 2015.

[66] M. Karbowski and A. Neutzner, - Neurodegeneration as a consequence of failed mitochondrial maintenance, Il Acta Neuropathologica, vol. 123, no. 2. pp. 157-171, 2012.

[67] A. H. V Schapira, -Mitochondrial dysfunction in neurodegenerative diseases,॥ Neurochem. Res., vol. 33, no. 12, pp. 2502-2509, 2008.

[68] F. M. De Vrij, J. A. Sluijs, L. Gregori, D. F. Fischer, W. T. Hermens, D. Goldgaber, J. Verhaagen, F. W. Van Leeuwen, and E. M. Hol, -Mutant ubiquitin expressed in Alzheimer's disease causes neuronal death., „l FASEB J., vol. 15, no. 14, pp. 2680-2688, 2001.

[69] G. R. Pathare, I. Nagy, S. Bohn, P. Unverdorben, A. Hubert, R. Korner, S. Nickell, K. Lasker, A. Sali, T. Tamura, T. Nishioka, F. Forster, W. Baumeister, and A. Bracher, - The proteasomal subunit Rpn6 is a molecular clamp holding the core and regulatory subcomplexes together, II Proceedings of the National Academy of Sciences, vol. 109, no. 1. pp. 149-154, 2012.

[70] K. Palikaras, E. Lionaki, and N. Tavernarakis, -Coordination of mitophagy and mitochondrial biogenesis during ageing in C. elegans, ,I Nature, 2015.

[71] J. Yun and T. Finkel, —Mitohormesis,Il Cell Metab., vol. 19, no. 5, pp. 757-766, 2014.

[72] J. Durieux, S. Wolff, and A. Dillin, -The cell-non-autonomous nature of electron transport chain-mediated longevity,ll Cell, vol. 144, no. 1, pp. 79-91, 2011. 
[73] E. Owusu-Ansah, W. Song, and N. Perrimon, -XMuscle mitohormesis promotes longevity via systemic repression of insulin signaling,\| Cell, vol. 155, no. 3, pp. 699-712, 2013.

[74] K. Burkewitz, I. Morantte, H. J. M. Weir, R. Yeo, Y. Zhang, F. K. Huynh, O. R. Ilkayeva, M. D. Hirschey, A. R. Grant, and W. B. Mair, -Neuronal CRTC-1 Governs Systemic Mitochondrial Metabolism and Lifespan via a Catecholamine Signal,II Cell, vol. 160, no. 5, pp. 842-855, 2015.

[75] M. Lazarou, D. a. Sliter, L. a. Kane, S. a. Sarraf, C. Wang, J. L. Burman, D. P. Sideris, A. I. Fogel, and R. J. Youle, -The ubiquitin kinase PINK1 recruits autophagy receptors to induce mitophagy, II Nature, 2015.

[76] C. M. Haynes, K. Petrova, C. Benedetti, Y. Yang, and D. Ron, -ClpP Mediates Activation of a Mitochondrial Unfolded Protein Response in C. elegans, II Dev. Cell, vol. 13, no. 4, pp. 467-480, 2007.

[77] N. Al-Furoukh, A. Ianni, H. Nolte, S. Hölper, M. Krüger, S. Wanrooij, and T. Braun, - ClpX stimulates the mitochondrial unfolded protein response (UPRmt) in mammalian cells,ll Biochim. Biophys. Acta - Mol. Cell Res., 2015.

[78] C. L. Nezich, C. Wang, a. I. Fogel, and R. J. Youle, -MiT/TFE transcription factors are activated during mitophagy downstream of Parkin and Atg5,\| J. Cell Biol., vol. 210, no. 3, pp. 435-450, 2015.

Highlighted references:

- [1] A. M. Nargund, C. J. Fiorese, M. W. Pellegrino, P. Deng, and C. M. Haynes, -Mitochondrial and Nuclear Accumulation of the Transcription Factor ATFS-1 Promotes OXPHOS Recovery during the UPRmt,ll Mol. Cell, vol. 58, no. 1, pp. 123-133, 2015.

In this paper the authors identify a transcriptional crosstalk between the genomes of both the nucleus and mitochondria in response to mitochondrial stress by ChIP-seq. The balanced expression of respiratory chain components as well as factors supporting mitochondrial proteostasis is required to promote functional recovery of mitochondria.

- [13] C. N. Cunningham, J. M. Baughman, L. Phu, J. S. Tea, C. Yu, M. Coons, D. S. Kirkpatrick, B. Bingol, and J. E. Corn, —USP30 and parkin homeostatically regulate atypical ubiquitin chains on mitochondria,\|l Nat. Cell Biol., vol. 17, no. 2, pp. 160-169, 2015.

This paper brings evidence how ubiquitylation by parkin and deubiquitylation by USP30 regulates mitochondrial homeostasis. Upon mitochondria damage parkin assembles K6, K11 and K63 chains on mitochondria, while USP30 preferentially removes the same linkage types from ubiquitylated intact mitochondria. USP30 therefore counteracts parkin-mediated ubiquitin chain formation and is involved in mitophagy regulation.

- [26] E. S. Vincow, G. Merrihew, R. E. Thomas, N. J. Shulman, R. P. Beyer, M. J. MacCoss, and L. J. Pallanck, -The PINK1-Parkin pathway promotes both mitophagy and selective 
respiratory chain turnover in vivo., II Proc. Natl. Acad. Sci. U. S. A., vol. 110, no. 16, pp. $6400-$ 5, 2013.

This proteomics analysis of mitochondrial protein degradation in Drosophila identified that besides generally promoting proteins turnover, PINK-Parkin also determines selective turnover of subunits of the respiratory chain complexes.

- [33] R. J. Braun, C. Sommer, C. Leibiger, R. J. G. Gentier, V. I. Dumit, K. Paduch, T. Eisenberg, L. Habernig, G. Trausinger, C. Magnes, T. Pieber, F. Sinner, J. Dengjel, F. W. van Leeuwen, G. Kroemer, and F. Madeo, -Accumulation of Basic Amino Acids at Mitochondria Dictates the Cytotoxicity of Aberrant Ubiquitin,\| Cell Rep., vol. 10, no. 9, pp. 15571571, 2015.

This study implicates that the MAD pathway via Vms1 is relevant for the detoxification of an aberrant ubiquitin molecule that is linked to Alzheimer's disease.

- [34] S. A. Sarraf, M. Raman, V. Guarani-Pereira, M. E. Sowa, E. L. Huttlin, S. P. Gygi, and J. W. Harper, -Landscape of the PARKIN-dependent ubiquitylome in response to mitochondrial depolarization.,\|l Nature, vol. 496, no. 7445, pp. 372-6, 2013.

A proteomic approach has identified numerous ubiquitylation targets of Parkin upon mitochondria depolarization. These targets are enriched in mitochondrial outer membrane proteins indicating that Parkin has its primary targets on the mitochondria.

This study describes systematic target identification and ubiquitylation site detection in PARKIN-mediated ubiquitylation.

- • [41] F. Koyano, K. Okatsu, H. Kosako, Y. Tamura, E. Go, M. Kimura, Y. Kimura, H. Tsuchiya, H. Yoshihara, T. Hirokawa, T. Endo, E. a Fon, J.-F. Trempe, Y. Saeki, K. Tanaka, and N. Matsuda, -Ubiquitin is phosphorylated by PINK1 to activate parkin.,"l Nature, vol. 510, no. 7503 , pp. 162-6, 2014.

This paper describes that ubiquitin is phosphorylated by PINK1 at serine 65 position. PINK1-dependent phosphorylation of both parkin and ubiquitin is necessary for full activation of parkin E3 ligase activity and subsequent induction of selective autophagy of damaged mitochondria.

- - [42] L. A. Kane, M. Lazarou, A. I. Fogel, Y. Li, K. Yamano, S. A. Sarraf, S. Banerjee, and R. J. Youle, -PINK1 phosphorylates ubiquitin to activate parkin E3 ubiquitin ligase activity,ll J. Cell Biol., vol. 205, no. 2, pp. 143-153, 2014.

This paper describes that ubiquitin is phosphorylated by PINK1 at serine 65 position. PINK1-dependent phosphorylation of both parkin and ubiquitin is necessary for full activation of parkin E3 ligase activity and subsequent induction of selective autophagy of damaged mitochondria.

- - [43] A. Kazlauskaite, C. Kondapalli, R. Gourlay, D. G. Campbell, M. S. Ritorto, K. Hofmann, D. R. Alessi, A. Knebel, M. Trost, and M. M. K. Muqit, -Parkin is activated by PINK1-dependent phosphorylation of ubiquitin at Ser65.,Il Biochem. J., vol. 460, no. 1, pp. 127-39, 2014. 
This paper describes that ubiquitin is phosphorylated by PINK1 at serine 65 position. PINK1-dependent phosphorylation of both parkin and ubiquitin is necessary for full activation of parkin E3 ligase activity and subsequent induction of selective autophagy of damaged mitochondria.

- [44] K. Okatsu, M. Kimura, T. Oka, K. Tanaka, and N. Matsuda, —Unconventional PINK1 localization to the outer membrane of depolarized mitochondria drives Parkin recruitment, $\| \mathrm{J}$. Cell Sci., vol. 128, no. 5, pp. 964-978, 2015.

By using a linear phosphomimetic tetra-ubiquitin(S65D) chain with a ubiquitin replacement strategy the authors of this paper have shown that Parkin is recruited to the mitochondria by phophorylated ubiquitin chains. Hence, ubiquitin phosphorylation is essential for Parkin translocation to the mitochondria.

- - [47] T. M. Durcan, M. Y. Tang, J. R. Pérusse, E. A. Dashti, M. A. Aguileta, L. Mclelland, P. Gros, T. A. Shaler, D. Faubert, B. Coulombe, and E. A. Fon, -USP 8 regulates mitophagy by removing K 6 -linked ubiquitin conjugates from parkin,\|l vol. 33, no. 21, pp. 2473-2491, 2014.

The authors have identified the deubiquitylating enzyme USP8 as a novel regulator of mitochondrial quality control. USP8 deubiquitylates Parkin, which enhances Parkin recruitment to the depolarized mitochondria and subsequent removal of the damaged organelle by mitophagy.

- - [48] T. Cornelissen, D. Haddad, F. Wauters, C. Van Humbeeck, W. Mandemakers, B. Koentjoro, C. Sue, K. Gevaert, B. De Strooper, P. Verstreken, and W. Vandenberghe, -The deubiquitinase USP15 antagonizes Parkin-mediated mitochondrial ubiquitination and mitophagy., II Hum. Mol. Genet., vol. 23, no. 19, pp. 1-45, 2014.

The authors of these papers identified the deubiquitylating enzyme USP15 as an antagonist of Parkin. USP15 counteracts Parkin-mediated ubiquitylation of depolarized mitochondria and attenuates Parkin-induced mitophagy through its DUB activity.

- • [49] B. Bingol, J. S. Tea, L. Phu, M. Reichelt, C. E. Bakalarski, Q. Song, O. Foreman, D. S. Kirkpatrick, and M. Sheng, - The mitochondrial deubiquitinase USP30 opposes parkin-mediated mitophagy., Il Nature, vol. 509, no. 7505, pp. 370-5, 2014.

This paper describes that the mitochondria localized deubiquitylating enzyme USP30 inhibits PINK1/Parkin-driven mitophagy. USP30 removes ubiquitins that are attached by Parkin onto damaged mitochondria, and knockdown of Drosophila USP30 rescues the defective mitophagy phenotype of parkin/PINK1-deficient flies.

- • [50] T. Wauer, K. N. Swatek, J. L. Wagstaff, C. Gladkova, J. N. Pruneda, M. A. Michel, M. Gersch, C. M. Johnson, S. M. V Freund, and D. Komander, -Ubiquitin Ser65 phosphorylation affects ubiquitin structure, chain assembly and hydrolysis, II vol. 34, no. 3, pp. 307-325, 2015.

The authors have shown that PINK1 can phosphorylate every Ub at Ser65 position in any Ub chain. Phosphorylation of Ub alters its structure, that can affect discharging of E2 enzymes to form polyUb chains and also impairs deubiquitylating enzymes in hydrolyzing phosphoUb chains. Phosphorylation of ubiquitin therefore brings a new layer of regulation in the Ub system. 
- • [63] A. Segref, É. Kevei, W. Pokrzywa, K. Schmeisser, J. Mansfeld, N. Livnat-Levanon, R. Ensenauer, M. H. Glickman, M. Ristow, and T. Hoppe, -Pathogenesis of human mitochondrial diseases is modulated by reduced activity of the ubiquitin/proteasome system,ll Cell Metab., vol. 19, no. 4, pp. 642-652, 2014.

This paper identified a conserved link between mitochondrial stress and ubiquitindependent cytoplasmic protein degradation. The authors have shown that mitochondria dysfunction-driven increased ROS production impairs the ubiquitinproteasome system, which in humans can potentiate disease progression of several mitochondrial pathologies.

- [64] N. Livnat-Levanon, É. Kevei, O. Kleifeld, D. Krutauz, A. Segref, T. Rinaldi, Z. Erpapazoglou, M. Cohen, N. Reis, T. Hoppe, and M. Glickman, -Reversible 26S proteasome disassembly upon mitochondrial stress, II Cell Rep., vol. 7, no. 5, pp. 1371-1380, 2014.

This paper shows that acute oxidative stress caused by mitochondrial defects results in rapid disassembly of $26 \mathrm{~S}$ proteasomes into intact $20 \mathrm{~S}$ core and $19 \mathrm{~S}$ regulatory particles. The proteasome attenuation is dependent on cysteine oxidation of proteasome subunits and is of reversible nature.

- • [70] K. Palikaras, E. Lionaki, and N. Tavernarakis, -Coordination of mitophagy and mitochondrial biogenesis during ageing in C. elegans, „l Nature, 2015.

This paper analyzes the contribution of a controled mitochondrial mass through regulated biogenesis and degradation in a multicellular organism. They reveal that mitochondrial mass is carefully adapted to metabolic stress and during aging.

- [73] E. Owusu-Ansah, W. Song, and N. Perrimon, -XMuscle mitohormesis promotes longevity via systemic repression of insulin signaling,\|l Cell, vol. 155, no. 3, pp. 699-712, 2013.

Together with [64] this paper shows that mitochondrial dysfunction in an isolated tissue is capable of initiating adaptive regulatory mechanisms in distinct tissues and on organim level.

- [74] K. Burkewitz, I. Morantte, H. J. M. Weir, R. Yeo, Y. Zhang, F. K. Huynh, O. R. Ilkayeva, M. D. Hirschey, A. R. Grant, and W. B. Mair, -Neuronal CRTC-1 Governs Systemic Mitochondrial Metabolism and Lifespan via a Catecholamine Signal, II Cell, vol. 160, no. 5, pp. 842-855, 2015.

This paper reveals that the central nervous system plays a decisive role in the initiation of organism wide adaptive mechanisms upon metabolic disturbance affecting, mitochondrial morphology and function in distal tissues. 
Figure

Click here to download high resolution image 
(a)

Figure 1

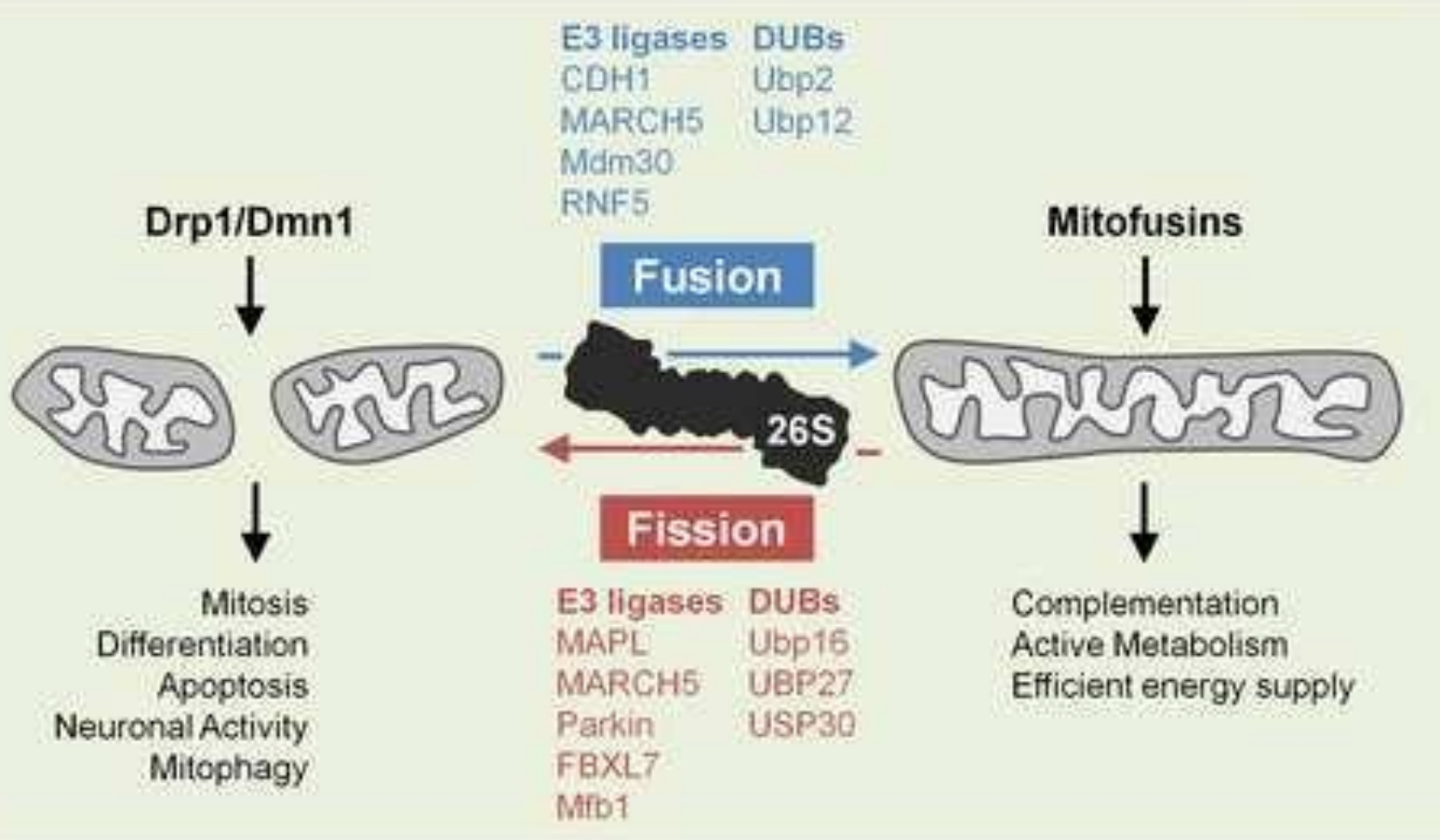

(b)

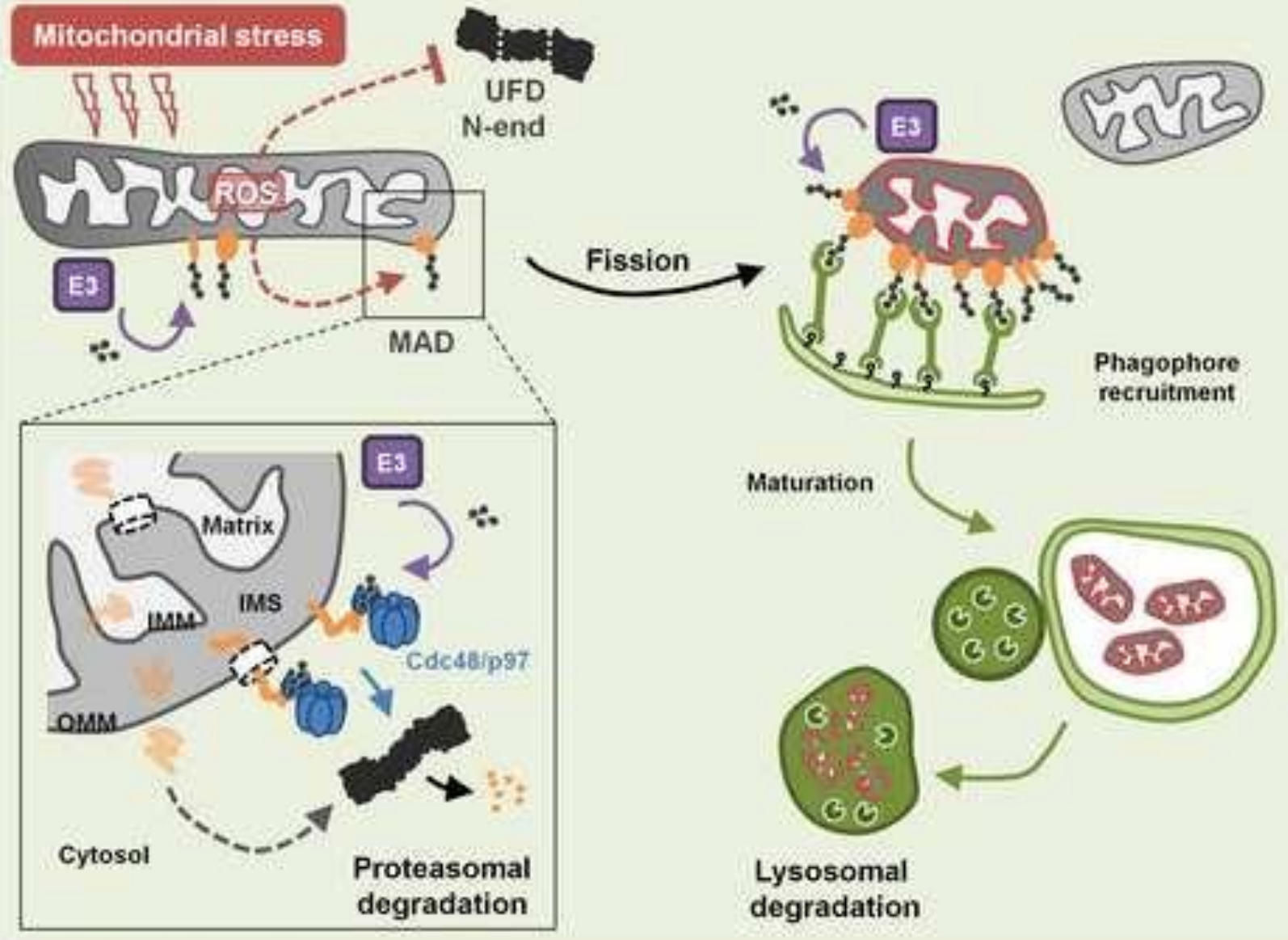


Table 1

UPS components governing mitochondrial dynamics, mitochondria-associated degradation (MAD) and mitophagy

\section{Mitochondria fission and}

UPS componentOrganism / system Substrate Reference fusion

\begin{tabular}{|c|c|c|c|c|}
\hline \multirow[t]{10}{*}{ E3 } & MAPL (Mulan, Mul1) & $\begin{array}{l}\text { mammalian cells } \\
\text { mammalian cells and Drosophila }\end{array}$ & $\begin{array}{l}\text { Drp1 } \\
\text { Mfn.Mfn1. Mfn2 }\end{array}$ & $\begin{array}{l}\text { Braschi et al. } 2009 \\
\text { Yun et al.. } 2014\end{array}$ \\
\hline & \multicolumn{4}{|c|}{ March5 (MITOL) mammalian cells Mfn2, Drp1 Nakamura et al. 2006 Mfn1 Park and Cho, 2012} \\
\hline & & & Drp1 & Karbowski et al. 2007 \\
\hline & & & Mfn2 & Sugiura et al. 2013 \\
\hline & & & Fis1 & $\begin{array}{l}\text { Yonashiro et al., } 2006 \\
\text { Fang et al. } 2013\end{array}$ \\
\hline & Parkin & mammalian cells & Mfn1 & Glauser et al. 2011 \\
\hline & & & Mfn1, Mfn2 & Gegg et al. 2010 \\
\hline & Huwe1/Mule & mammalian cells & Mfn2 & Leboucher et al., 2012 \\
\hline & APC/C Cdh1 complex & mammalian cells & Drp1 & Horn et al. 2011 \\
\hline & RNF5 & mammalian cells & Fis1 & Zhang et al. 2012 \\
\hline \multirow[t]{4}{*}{ DUB } & Ubp16 & yeast & & \multirow{4}{*}{$\begin{array}{l}\text { Kinner and Koelling } 2003 \\
\text { Pan et al. } 2014 \\
\text { Yue et al. } 2014 \\
\text { Nakamura and Hirose et al. } 2007 \\
\text { Anton et al. } 2012\end{array}$} \\
\hline & UBP27 & Arabidopsis & DRP3 & \\
\hline & USP30 & mammalian cells & Mfn1, Mfn2 & \\
\hline & Ubp2 and Ubp12 & yeast & Fzo1 & \\
\hline \multirow[t]{8}{*}{ F-box protein } & Fbxl7 & mammalian cells & Survivin & \multirow{8}{*}{$\begin{array}{l}\text { Liu et al. } 2015 \\
\text { Duerr et al. } 2006 \\
\text { Kondo-Okamoto et al. } 2006 \\
\text { Fritz et al. } 2003 \\
\text { Escobar-Henriques et al. } 2006 \\
\text { Cohen et al. } 2008 \\
\text { Cohen et al. } 2011 \\
\text { Duerr et al. } 2006\end{array}$} \\
\hline & Mfb1 & yeast & & \\
\hline & & & & \\
\hline & Mdm30 & yeast & Fzo1 & \\
\hline & & & Fzo1 & \\
\hline & & & Fzo1 & \\
\hline & & & Fzo1 & \\
\hline & & & & \\
\hline MAD & UPS component & Organism / system & Substrate & Reference \\
\hline
\end{tabular}




\begin{tabular}{|c|c|c|c|c|}
\hline E3 & Mulan & Drosophila & $\begin{array}{l}\text { Mfn1 Mcl1 } \\
\text { Mfn1 Mfn2 } \\
\text { variety of substrates } \\
\text { Mfn1 } \\
\text { Mfn1, Mfn2 } \\
\text { respiratory chain } \\
\text { components } \\
\text { Mitofusins }\end{array}$ & $\begin{array}{l}\text { Xu et al. } 2010 \\
\text { Tanaka t al. } 2010 \\
\text { Sarraf et al. } 2013 \\
\text { Glauser et al. } 2011 \\
\text { Gegg et al. } 2010 \\
\text { Vincow et al. } 2013 \\
\\
\text { Tyun et al. } 2013\end{array}$ \\
\hline AAA family ATPase & Cdc48/p97 & $\begin{array}{l}\text { mammalian cells } \\
\text { Fang et al. } 2015 \text { mammalian cells ar }\end{array}$ & $\begin{array}{l}\text { Mfn1 Mfn2 } \\
\text { Mfn1 Mcl1 } \\
\text { nd Drosophila }\end{array}$ & $\begin{array}{l}\text { Tanaka t al. } 2010 \\
\text { Xu et al. } 2010 \\
\text { Hemion et al. } 2014 \\
\text { al. } 2013\end{array}$ \\
\hline Cdc48 cofactor & Vms1 & yeast and $C$. elegans & & Heo et al. 2010 \\
\hline Mitophagy & UPS component & Organism / system & Substrate & Reference \\
\hline E2 & $\begin{array}{l}\text { UBE2A } \\
\text { UBE2N, UBE2D2, } \\
\text { UBE2D3, UBE2L3 } \\
\text { UBE2N, UBE2D2, } \\
\text { UBE2D3, UBE2L3 } \\
\text { UBE2R1/CDC34 } \\
\text { Ube2E3 }\end{array}$ & $\begin{array}{l}\text { mammalian cells and Drosophila } \\
\text { mammalian cells } \\
\text { mammalian cells } \\
\text { mammalian cells } \\
\text { mammalian cells }\end{array}$ & $\begin{array}{l}\text { Parkin substrates } \\
\text { Parkin substrates } \\
\text { Parkin substrates }\end{array}$ & $\begin{array}{l}\text { Haddad et al., } 2013 \\
\text { Geisler et al., } 2014 \\
\text { Fiesel et al., } 2014 \\
\text { Fiesel et al., } 2014 \\
\text { Ambivero et al., } 2014\end{array}$ \\
\hline E3 & Parkin & $\begin{array}{l}\text { mammalian cells } \\
\text { mammalian cells and Drosophila }\end{array}$ & $\begin{array}{l}\text { Mff } \\
\text { VDAC1 } \\
\text { Miro Wanget al. 2C } \\
2012 \\
78 \text { mammalian cells }\end{array}$ & $\begin{array}{l}\text { Gao et al. } 2015 \\
\text { Geisler et al., } 2010 \\
11 \text { Miro } \quad \text { Liu et al. }\end{array}$ \\
\hline & $\begin{array}{l}\text { Mulan } \\
\text { Mul1 } \\
\text { RNF185 }\end{array}$ & $\begin{array}{l}\text { C. elegans Palikaras et el. } 2015 \mathrm{Gp} \\
\text { mammalian cells } \\
\text { mammalian cells } \\
\text { mammalian cells }\end{array}$ & $\begin{array}{l}78 \text { mammalian cells } \\
\text { Mfn2 } \\
\text { GABARAB } \\
\text { Ulk1 } \\
\text { BNIP1 }\end{array}$ & $\begin{array}{l}\text { Mfn1, Mfn2 Fu et al. } 2013 \\
\text { Lokireddy et al. } 2012 \\
\text { Ambivero et al., } 2014 \\
\text { Li et al., } 2015 \\
\text { Tang et al. } 2011\end{array}$ \\
\hline DUB & $\begin{array}{l}\text { USP8 } \\
\text { USP15 } \\
\text { USP30 } \\
\text { USP35 }\end{array}$ & $\begin{array}{l}\text { mammalian cells } \\
\text { mammalian cells and Drosophila } \\
\text { mammalian cells } \\
\text { mammalian cells }\end{array}$ & $\begin{array}{l}\text { Parkin } \\
\text { Parkin substrates }\end{array}$ & $\begin{array}{l}\text { Durcan et al., } 2014 \\
\text { Cornelissen et al. } 2014 \\
\text { Bingol et al., 2014; } \\
\text { Wang et al., 2015 }\end{array}$ \\
\hline
\end{tabular}


Table 2

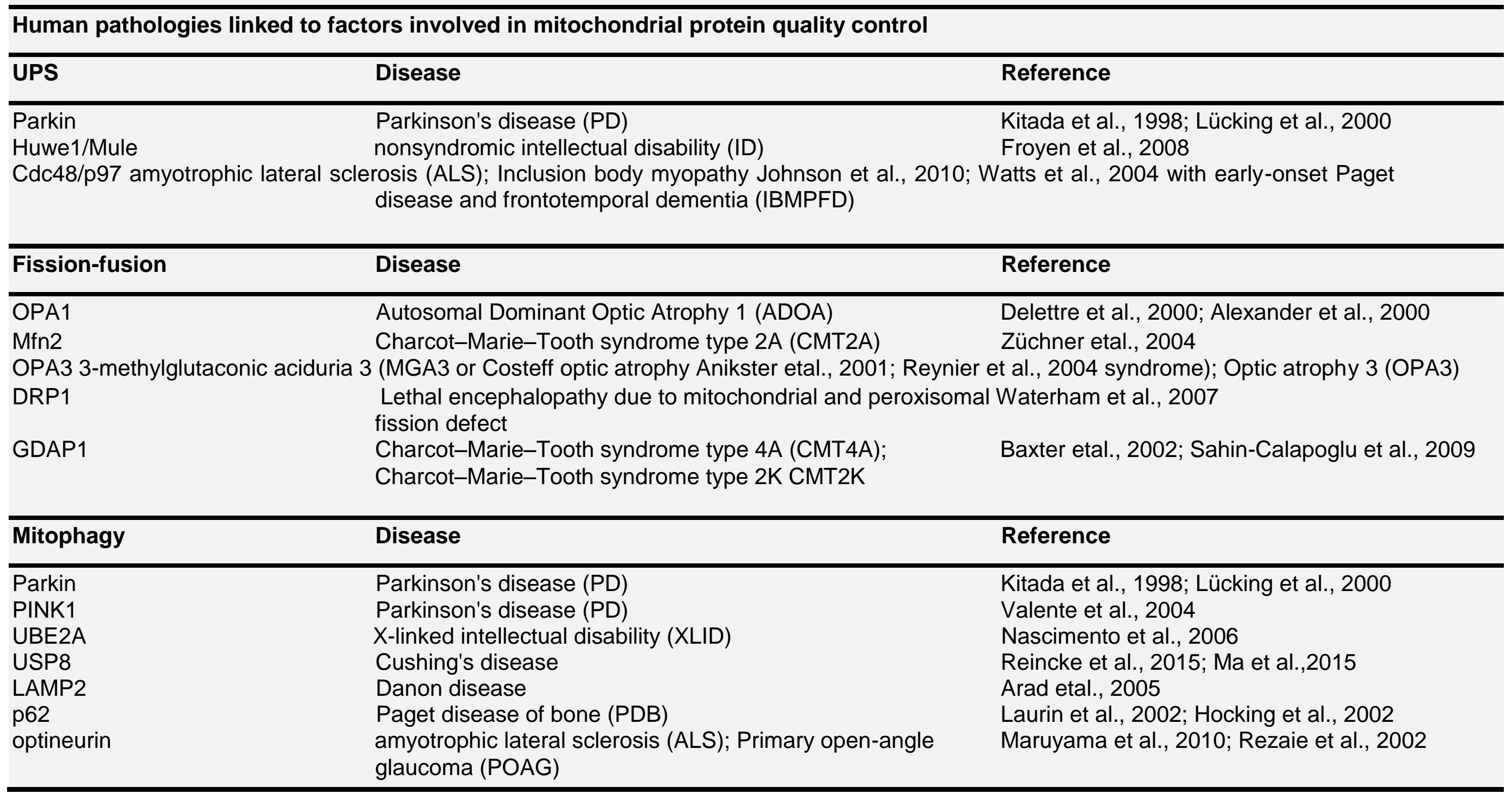

